\title{
Students' Perceptions of Social Presence in Blended Learning Courses in a Tanzanian Medical College
}

\author{
https://doi.org/10.3991/ijet.v13i09.8566 \\ Mustapha Almasi( $\left.{ }^{\bowtie}\right)$, Chang Zhu \\ Vrije Universiteit Brussel, Brussels, Belgium \\ mustapha.almasi@vub.be
}

\begin{abstract}
Social presence in a blended learning involves construction of learning through student sharing, interaction and support thus improving students' motivation, and learning. This paper examines students' perceptions of social presence (SP) in blended learning courses (BL) in a medical college in Tanzania. Three research questions are addressed: are there significant differences in the reported scores of SP among students based on gender, age and year of study? How is SP encouraged in the BL medical courses? How is SP associated with students' learning in the BL medical courses? Following a mixed method, Social Presence Scale and Focus Group Discussion were used in data collection. BL in these courses included face-to-face lectures, student online and face-to-face group discussions, laboratory practices, team-based learning (TBL), and online exams. The study involved 144 medical students. Survey results showed no significant differences in the reported scores of SP based on students' characteristics. However, affective expression and open communication were more valued than group cohesion elements of SP. Qualitative results showed that SP was encouraged through provision of group assignments, teacher online activities, and students' group discussions. Through SP and interaction, students learnt various concepts and examination questions in both online and in face-to-face discussions. The conclusion is that students' characteristics were not crucial, however, group discussion and SP influenced their learning.
\end{abstract}

Keywords—-social presence, blended learning, perception, student learning

\section{Introduction}

The concept of presence which is defined as "the act of being there despite physical separation" [1] has attracted attention in educational research for several years. Nevertheless, following the introduction of online learning, the concept of presence became more difficult to define and express it's influence in learning. Viewing presence from the student's point of view, [2] define it as the student's sense of being and belonging in a course; ability to interact with other students and an instructor although physical contact is not available. The author's definition was focused on online learning. In blended learning, which is defined as a thoughtful integration of face-to-face learning and online or web-based instruction, the concept of presence takes a different 
shape, as physical contact exists. In this case, presence involves student's sense of being, belonging to, and participating and interacting in a blended learning course. This interaction occurs between student and course content, instructor and student, and student and fellow students in both online and offline settings [3].

Social presence in a blended learning context entails construction of learning through peer participation, interaction and support [4]. This study approached social presence as one of the three elements of the community of inquiry (CoI). The community of inquiry is a framework which views learning as occurring through collaboration of students and instructors in the context of teaching, social and cognitive presences [5].

Students in a community of inquiry must feel free to express themselves openly in a risk-free manner [6]. They must be able to develop the personal relationships necessary to commit to and pursue intended academic goals and gain a sense of belonging to the community. The intended instructional effect of social presence is to facilitate collaboration, participation; peer evaluation and peer reflection that contributes to forming a blended community of learning [4]. In line with the CoI, social presence helps to identify with others, learn something about other students, and relate to the individual experiences of colleagues and appreciating other students' point of view [7].

Moreover, SP is a mediating factor which provides context for the educational process [8]. However, some researchers have warned of the negative effects that student's interaction/presence may have. Commenting on this, [2] argues that student interaction in web-based learning may be disruptive thus leading students to being misinformed. This, according to the author, is due to the nature of asynchronous discussion which allows students to interact in a variety of ways, sometimes causing the instructor to lose track and fail to comment on the correctness of students' views. This implies that to provide desired learning effects; social presence needs to be guided by direct instruction, facilitation and course design (teaching presence).

Several studies have investigated SP using mainly transcript analysis and SP scales. This study investigates students' perceptions of social presence using SP scale and FGD involving students in blended learning medical courses. The study is unique and significant in two ways: First, it examines SP in a Tanzanian Medical College where blended learning is still emerging. Second, the study uses students' experiences of SP and their perceptions as obtained in qualitative and quantitative data. This widens the empirical understanding of SP in a broader perspective.

\subsection{The genesis of social presence}

The genesis of the construct SP can be traced back to Mehrabian's (1969) concept of immediacy, which he defined as "those communication behaviors that enhance closeness to and nonverbal interaction with another" (p. 203) cited in [9]. Defining SP continues to be a debate among researchers and theorists depending on their disciplines and orientations. Later in 1970s, communication theorists, Short, Williams and Christie developed the initial theory of SP. They defined it as "the salience of the other in a mediated communication and the consequent salience of their interpersonal 
interactions" as quoted in [9]. The authors regard SP as an important part of communication medium which determine the way people communicate and interact. Social presence in in 1970s was conceived from communication studies. Later in 1980s and 1990s, when computer mediated communications became rampant, the concept was still perceived as antisocial and impersonal since social cues were filtered out during communication. In the late 1990 s, some researchers in education, started viewing SP as social and personal as well as opposed to the previous antisocial and impersonal conceptions.

In the year 2000, [6] published their community of inquiry framework which contains social, cognitive and teaching presence as key elements in explaining the learning community in online and later blended learning environment. In this respect, SP was viewed in the context of education and learning and not as a communication concept. However, the concept of SP arose from concerns among some communications scholars that computer-mediated communication might prevent students from developing the sense of belonging with other students, instructors, and programs of study which social learning theories suggest support learning [10].

\subsection{Dimensions and measurement of social presence}

Social presence in the light of the CoI framework contains three elements. These are open communication, cohesive responses (group cohesion) and affective/personal connections. Open communication entails reciprocal and respectful exchanges interactions [5]. Mutual awareness and recognition are examples of open communication. While mutual awareness helps to build group cohesion, recognition stimulates development and sustenance of exchange relationships [5]. The authors [5] indicate that in general, open communication encompasses free expression, respectful attending to the comments and contributions of others, appreciating, encouraging, and complementing other during learning. The second element of SP is affective expression or personal connections. Affective expression is related to emotional expression. This aspect has been defined as the ability to express feelings related to educational experience [5]. This includes expression of emotions, features of text used to convey emotion (emoticons), use of humor and self-disclosure. For instance, students in an online group discussion may use various emoticons such as an index finger pointing up to indicate 'like' or an icon showing 'smile' to indicate feelings of happiness. The use of humor in social interactions tends to decrease social distance and convey good will. Selfdisclosure entails personal revelation which helps to build trust and help in knowing each other [5]. For instance, a student may share personal information with course group members like "I had a similar problem in accessing the internet when trying to define SP". The third element of SP is group cohesion. Group cohesion refers to a sense of group commitment. This part of SP makes students see themselves as part of the group. Use of cohesive indicators indicates group cohesion. Cohesive indicators include group reference terms such as referring to the group as 'we', vocatives such as calling each other by names, social sharing such as informing fellow students about one's birthday or a funeral, and greetings and salutations. 
Understanding the role of SP is essential in creating a community of inquiry and in designing, facilitating, and directing higher-order learning [11]. SP construct has been measured in two ways. On the one hand, the measure of SP has been done using SP scales. SP scale has been used by many researchers such as [12], and [13]. On the other hand, SP, has been measured by obtaining students and instructors chat forums and conduct transcript analysis to find out the amount of SP. This method has been used by many researchers such as [14, [9], [15]. This study examined SP using SP Scale, and FDG with students. While SP scale quantitatively measured the perception of SP, FGD questions explored students' experiences SP in their BL courses.

\subsection{Social presence and student learning}

Research on SP and students' learning has generated various findings. For instance, while some researchers show that SP increases interaction, predict students' performance, relates to student learning, it was not related to exams score [7]. Other studies conducted in higher education show that SP influences interaction, communication, improves learning, and student satisfaction and motivation [7]; [16]. The researchers [16] examined SP in the online environment and its relationship to students' performance. The findings showed a relationship between SP, students' performance, and satisfaction with instructors. SP predicted students' performance. In his study [1], SP was encouraged using techniques fostering a sense of presence and sense of community. Overall, the findings suggested a strong relationship among perception of interaction, SP, and learning.

\section{Method}

A mixed design method was used to investigate students' perceptions of SP in the two blended learning courses at Kilimanjaro Christian Medical University College (KCMUCo), Kilimanjaro, Tanzania. Both quantitative and qualitative data were gathered concurrently. SP scale for studying SP was used, followed by FGD with students. The following research questions were addressed in this paper;

1. Are there differences in student report of social presence based on gender, age and year of study?

2. How is social presence encouraged in the medical blended learning courses?

3. How is social presence associated with students' learning in the medical blended learning courses?

\subsection{Participants}

The study involved144 first and second year medical students at KCMUCo in Kilimanjaro, Tanzania. Out of the 144 respondents, 137 (95\%) filled the questionnaires completely. Two courses (anatomy for Medical I students and Microbiology for Medical II students) taught in BL mode were selected. Out, of these students, $89(62 \%)$ 
were male while $48(33 \%)$ female. Most respondents $131(91 \%)$ were aged between 20-27, while those $28-35$ were (5) $3.5 \%$ and those above 36 were only (1) $0.7 \%$. First year students (anatomy course) were (74) 52\% and second year (microbiology course) were $43.2 \%$ (63) while (7) $4.9 \%$ did not indicate their year of study. The two BL courses of anatomy and microbiology, and first and second year students were selected based on their engagement in BL activities and their availability to participate in the study as sophomore students were not readily accessible. Table 1 shows students' demographics.

Table 1. Students' demographics in frequency and percentage

\begin{tabular}{|l|c|c|}
\hline \multicolumn{2}{|c|}{ Type of variable } & Age \\
\hline $20-27$ & 131 & 91 \\
\hline $28-35$ & 5 & 3.5 \\
\hline 36 and above & 1 & 0.7 \\
\hline Missing & 7 & 4.8 \\
\hline Total & $\mathbf{1 4 4}$ & $\mathbf{1 0 0}$ \\
\hline & Gender & 62 \\
\hline Male & 89 & 33.2 \\
\hline Female & 48 & 4.8 \\
\hline Missing & 7 & $\mathbf{1 0 0}$ \\
\hline Total & $\mathbf{1 4 4}$ & \\
\hline & \multicolumn{3}{|c|}{ Year of study } & 52 \\
\hline First year & 74 & 43.2 \\
\hline Second year & 63 & 4.8 \\
\hline Missing & 7 & $\mathbf{1 0 0}$ \\
\hline Total & $\mathbf{1 4 4}$ & \\
\hline
\end{tabular}

\subsection{Context and Procedure}

This study involved two BL medical courses at a medical college in Tanzania. The courses were Anatomy and Microbiology studied by Medical I and II students at KCMUCo. Both courses were taught through blended learning. Part of the teaching occurred in face-to-face sessions through lectures, team-based learning, question and answer sessions, demonstrations and practical in the laboratory, and online discussions in the Moodle and (LCMS+) learning systems. Students accessed the LMSs for lecture notes, TBL and online discussions and examinations. All students involved in the study voluntarily agreed to take part in the study after the lead author sought their informed consent. The lead author solicited the consent verbally from the students. The informed consent was obtained by students verbally agreeing to take part in the study. Permission to involve the students was obtained from the Dean of Students. To ensure confidentiality and anonymity students were told to use pseudonyms during the group discussions. 


\subsection{Instruments and Measurements}

Social presence was quantitatively measured using SP scale. The study employed a mixed method approach in data collection and analysis. Nine survey questions were used to measure SP. The surveys were provided by the lead author in person. Students were provided with surveys in their classes after permission from their instructors. Students filled and returned the questionnaires in about 30 minutes. The survey also included students' characteristics such as year of study, course name, gender and age. Students were asked to rate their SP based on a 5-point Likert Scale ranging from 1 (Strongly Disagree to 5 Strongly Agree). The SP construct included three dimensions; affective expression, open communication, and group cohesion. Some of the questions in the survey included, getting to know other course participants gave me a sense of belonging in the course, I was able to form distinct impressions of some course participants, measuring affective domain. Open communication covered questions such as, I felt comfortable conversing through the online medium, and I felt comfortable participating in the course discussions. Group cohesion domain covered questions like, I felt comfortable disagreeing with other course participants while still maintaining a sense of trust and I felt that my point of view was acknowledged by other course participants.

Qualitative data were obtained using FGD. Three group of students volunteered for the FGD. The groups made a total of 15 students. Qualitative data included students' transcripts of their SP obtained in the FGD. The FGDs were tape recorded and written down by the assistant moderators during the discussion. Each focus group lasted for about one hour and twenty minutes on average. Students were informed about the objectives of the FGD. The key questions asked were; which social-learning activities bring you together to create social presence in the BL courses you are taking? How do you encourage social presence in the BL course you are taking? Do you feel connected with certain students in the BL course you are taking? why or why not? How do you associate your social presence with your learning in the course?

\subsection{Data analysis}

Both quantitative and qualitative data were obtained in this study. Students' characteristics were analysed using descriptive analysis methods. Mann Whitney and Kruskal Wallis tests were used to analyse the differences in the reported scores of SP and students' characteristics. Qualitative data were transcribed into the text. Based on the nature of the data, a combination of inductive and deductive approaches to the content analysis was employed. The sentence was used as the unit of analysis. First, all open codes in the sentences were listed, later reduced to10 codes. Pre-coded themes were obtained from the data. The pre-coded themes were based on an understanding of SP in the light of the CoI model and SP indicators as in [13]; [9]. These themes were those related to SP indicators as defined in the CoI. These included the use of group references, social sharing, as indicators of group cohesion, humor, for as affective indicator etc. 


\section{$3 \quad$ Findings}

This part presents the findings of the study beginning with the quantitative findings which are explained by the qualitative results. Students involved in the FGD are given short codes as pseudo names, for instance RIM, for respondent 1 medical I, while RIM2 for respondent 1 medical II.

\subsection{Reliability and Validity of the SP scale}

The SP scale contained 9 items. The reliability analysis showed that the SP scale was highly reliable for data collection. The scale has overall Cronbach alpha $=.87$ which is high and acceptable. The sub-scales of the survey reliability were as follows: $(\alpha=.74)$, for affective expression, open communication $(\alpha=.79)$, and group cohesion $(\alpha=.64)$ which was below the .70 standard. Overall, the SP scale was reliable. Table 2 shows the reliability of the SP scale.

\subsection{Students' characteristics and their perceptions of social presence}

The study measured students' perceptions of SP and related them with their characteristics. Students' characteristics included age, gender, and year of study (course type). To measure students' perceptions of SP, an SP scale was used. Then, the researchers compared the reported scores of SP between male and female students. The results of the Mann Whitney U test, showed Male students reported high mean rank score of SP (69) compared to Female students (67). However, the difference was nonsignificant. $(U=2058, p=.724)$. This means, there was no significant difference in the reported scores of SP between male and female medical students.

Secondly, a Mann Whitney U test was conducted to find out if there was any significant difference in the scores of SP among first year (anatomy course) and second year students (Microbiology course). The results of the Mann Whitney U test showed that there was a non-significant difference in the reported scores of SP between first and second year students $(U=2880, p=.809)$. However, first year students reported a slightly higher mean score (69) compared to that of second year students (68). This also means that there was no significant difference in the mean scores of the two groups based on the courses they studied, ie Microbiology and Anatomy. Again, Kruskal Wallis test was run to find out if there was a significant difference between age and reported scores of SP among students. The results of the Kruskal Wallis test showed that there was no significant difference in the reported scores of SP among the age groups $\left(\chi^{2}(2)=.570, p=.752\right)$.

Mean scores of the sub-scale highly and lowly rated in social presence

Based on the mean scores, students highly rated affective expression items ( $\mathrm{M}=$ $3.89, \mathrm{SD}=1.01)$ and open communication $(\mathrm{M}=3.85, \mathrm{SD}=1.02)$. The results of the qualitative data showed that in the studied blended courses, face-to-face contacts increased the amount of social interaction among students which were maximized during online discussions especially in the social media groups, and during TBL sessions. This is substantiated by the students' responses in the FGD who mentioned that 
they spoke openly in their group discussions, moved, lived together, shared the same class sessions, and shared social gatherings such as going to church together. This can also be explained by items related to affective expression and open communication being highly rated.

Surprisingly, group cohesion scored the lowest mean $(\mathrm{M}=3.54, S D=1.03)$. Perhaps this is due to the nature of the online discussions, which took place at specific times, such as night (for students who lived far) or during exams (in which only questions were discussed) thus limiting online discussions and collaborations. This was noted during the FDG responses. In the FGDs students also reported that they mainly responded to friends or people they knew during their discussions, as they thought, others only wanted to challenge them. Table 2 shows the descriptive statistics of SP and their reliability.

Table 2. Descriptive statistics and reliability of SP subscales

\begin{tabular}{|l|c|c|c|}
\hline \multicolumn{1}{|c|}{ SP subscale } & Means (M) & Standard deviation (SD) & Cronbach Alpha \\
\hline Affective expression & 3.89 & 1.01 & .74 \\
\hline Group cohesion & 3.54 & 1.03 & .64 \\
\hline Open communication & 3.85 & 1.02 & .79 \\
\hline
\end{tabular}

\subsection{How is social presence encouraged in the blended learning courses?}

The second objective examined how SP was encouraged in the studied BL courses. First, students were asked what activities and how such activities encouraged SP in the courses they studied. In the FGD, students mentioned face-to-face class sessions, exclusive face-to- face group discussions, online (WhatsApp and LMS forum) discussions, instructor online questions, learning materials, class lectures, laboratory works, group assignments and studying together in the class as activities which brought them close together. This is to say student based interactive activities, both online and offline, and teacher-based activities (teaching presence) such as questions posted online, and lecture sessions, provided students with a sense of SP in the courses facilitated students' SP. This finding suggests that both teaching presence and student participation and interaction are important in exerting SP among students. Although students mentioned various activities, further analysis showed that group discussion was the major way which encouraged students' SP. This was evident in the FGD in which almost every student mentioned group discussion as their anchoring unit. The following are some of the responses from the FGD expressing social interactive activities which brought students together.

"The class teacher brings us together as he provides materials on the eLearning system where we meet online especially in the computer lab. We meet in MDI hall, where we have classes on Monday and Friday." R1M.

Another medical I respondent added on the influence of group discussion,

"We have group discussions we conduct face-to-face and we also have online group discussions. We have a group where we discuss things in the WhatsApp group" $R 4 M$ 
A similar response was made by R3M2 who said,

"On my side, something that brings us together in this course is studying together in the classroom, especially our microbiology instructor, he teaches and asks questions in the class. This makes me feel confident. Also, group discussion and when the teacher gives us assignments".

These excerpts from the respondents show the importance of teaching presence, and student group discussions in enhancing SP. In the FDG, students used various indicators of group cohesion such as group reference terms like "we", "our" when responding to various questions. This also signifies their sense of belonging to their groups and that they learned together.

Furthermore, students' sense of SP was also showed in the way they put personal touches and use emoticons in their communication during learning and discussions. In the FGD students expressed that they used emoticons to show appreciation, to bond with others, to feel and get closer, save time, and attract attention. Students believed that putting personal touches in their messages and using emoticons is showing wisdom and telling the kind of person that you are. They further elaborated that using emoticon symbols such as "smile" or "like" when posting and discussing online helped to save time and show care. The following responses from the FGD illustrate students' use of emoticons and personal touches.

"Why using emoticons? The way I get it is why don't we use formal language in our discussions when we are learning! That's how I got it. However, to be frank Mr. $J . K$, the goodness of the emoticons is that it brings you close to the person. It's like you are showing yourself to that person, like you are facing the person. For example, when you show someone a smile icon, it's like you are with that person. Those images help to express what we feel to that person. Just like my friend said, this shows that we are that kind of person, eg humble when using a humble imagery or icon". MR7

Another respondent added.

"I want to add something here when my colleague mentioned that using emoticons is our common language. It is showing wisdom. This is to avoid using languages that may make others feel bad. So, we use images to draw people's attention". MR5

The use of emoticons to express feelings and sense of presence has been one of the major findings of this study. Students tended to use emoticons and put personal touches in their messages to make others "feel" their presence. This kind of explanation agrees with the formal definition of SP as the sense of feeling or ability to feel the presence. The use of emoticons to save time is an interesting paradox. Students felt that the use of icons such as a symbol of two hands folded together, express the idea of "thanks" faster than the use of the writings itself. On this, one respondent mentioned.

"Images (emoticons) such as those of showing thanks using an icon save time. Instead of taking much time to write, we use images" MR3

Since SP encompasses the idea of participation and connection. When asked whether they feel connected in these BL courses, most students related that they felt connected especially in their exclusive group discussions. In such groups they were free to ask each other without a sense of fear. However, some students felt connected mainly with people who answered their questions well. Online groups did not bond 
students together. This is because the groups were only active at certain times, such as examination period in which students posted questions, or at night where students could not come together. During other times, the online groups were used for posting notes only. Expressing how exclusive discussion groups brought them together, and how free they are in such groups, a medical I respondent said,

"At the altar (this as a name assigned to a group discussion) we correct each other, we use open language, we ask anything to each other without fear" MR2.

This response shows how free students were to express themselves in their exclusive group discussions, something they did not express to feel in their traditional faceto-face class.

Though students felt connected in general, most students choose whom to respond to especially when they were being asked questions. Students indicated that they felt bonded with members of their discussion groups and friends. They felt that other students asked to challenge them. Moreover, they would only respond when they knew the answer. Otherwise they would search for the answers first before they do. In the FGD with Medical I students, one respondent mentioned,

"In some situation I am selective, and I feel connected to the people who respond well to me." MR3. The same responses were made by Medical II students as indicated in the following quotes;

"I am selective, with my friend, I will answer what I know. But if it is someone I don't know, I only answer the question if I know the answer, but if I don't know the answer, I will first Google (search over the internet)". M2R2

Taken in general, these quotes from the FGD indicate that students in these BL courses are mostly connected to their group members and friends in which they compete and challenge each other. In contrast some students were not selective about whom they responded to. They would respond to whoever asked them something. This is indicated by one respondent who replied.

"I don't choose whom to respond to. I listen to various answers from different people and tend to find the correct one. "MR4

\subsection{Social presence and students' learning}

The third objective of the study examined how students associate SP to their learning. To achieve this objective, students were asked to explain how they relate their social presence with their learning. The main question was, do you think your SP relate in any way with your learning (performance) in this course? How?

Data analysis of the FGD transcripts indicate that students related that social presence influenced their learning in the sense that they learnt various concepts, and examination questions through online and face-to-face discussions, classroom interactions, TBL sessions and interaction in the laboratory practical. During the FGD, a medical I explained how he learnt various concepts from an informal discussion he had with his friend.

"Social presence(interaction) helped me a lot, quite a lot. I remember one day we were walking with one of the members of our discussion group and discussing something. The following day we had an exam. I remember it was anatomy exam. We were 
talking about life, this and that and through talking he came up with a question and fortunately in the next exam, the question came up. Not only that, many times, we talked, and questions came in the exam". MR7.

A second-year medical student also added,

"I see social interactions and presence contribute in terms of learning. In Microbiology, you interact with your friends or fellow students when discussing exam questions, you get to know how to answer questions. In group discussion, someone comes and explains to you something you did not know, and you understand it". M2R2.

Interestingly, SP and interaction were also found to influence students' learning in another interesting way. Students were found to refer to each other by names of the structures they learnt in their anatomy course. This was testified by the students during the FGD.

"We use names of anatomical structures to call each other, for instance the name of Mr. Mgoo (not a student real name) is prob, Mr. Smile is digit mini. For example, they call me facialata. They used to call me longus before, following the names of structures we learnt in upper limbs anatomy". MR6

Importantly, students expressed that they learnt various things from the way their fellow students talked, used language, wrote and from mistakes that they committed while learning. For instance, students mentioned that they learnt how to pronounce some medical terms, how to write in good English, how to write politely through online discussion groups. They learnt wisdom from the way others used to apologize when they wrongly posted in the online discussions. Additionally, students narrated that interaction with fellow students changed their perceptions towards them. The following extracts from the FGD show how students relate social presence with their learning. Medical I student explained how others' mistakes helped her to learn.

"I wish to say personally that interaction with others helped me a lot. For instance, if you find somebody makes a mistake, that gives you a chance to make corrections. Yes, I can give an example, one day a student was asked to do an extension of muscles and unfortunately could not do it well, so when the lecturer corrected her, we all learnt how to do it"..MR5

Furthermore, another medical I student gave an example of learning language and wisdom from other students.

"Regarding posting messages in our WhatsApp groups, some would write in English and some would write in Kiswahili. Some write good English, they impress you to improve your English, so you learn like aah, so people write such and such good English words. Also, some people, when they make mistakes, there are words that they use to seek apology, such words tell you that these people have wisdom and that they are humble. I remember when some people made mistakes in their posts, they would send messages to ask for apologies, so I think of them as people with wisdom, that such people are not weak, not stubborn, and accept that they have made a mistake”. MR6

A student from medical II course also mentioned,

"The real interaction that holds an exalted position has to do with what the students publicly talk, that you need to study hard to pass microbiology, and that when you fail and get a supplementary it's hard to make it. So, you enter into the course 
with a strong attitude that am going to struggle, but when you start studying it, you find things go smoothly. You see yourself as passing, so you find that the interaction between you and other people makes you learn that such and such courses use this style and others use that style. I feel comfortable learning in a group discussion. How people present their ideas helped me to feel confident". $\mathbf{M} 2 \mathbf{R} 3$

Therefore, in general, students associated their social interactions and social presence with their learning as they learnt various concepts, key questions, and felt more confident through such encounters.

\section{Discussion}

This study investigated students' perceptions of social presence in blended learning courses at KCMUCo in Kilimanjaro, Tanzania.

The survey findings showed that there were no significant differences in the reported scores of SP regarding gender, age and year of study (course type). This implies that gender, age and year of study are not important variables in influencing social presence in these BL courses. Alike this study, [13] found no significant differences in perception of social presence based on gender and student classes. Also, studies by $[17,18]$ found no significant difference based on age indicating that SP exists in all learners regardless of their age. Regarding course type, differently, a study by [13] found a significant difference in the mean scores of SP between students taking Mass Communication and those taking Educational Computing. According to the author, the difference could be related to the instructional design. The medical courses studied in this study were very similar in structure both being descriptive basic medical sciences as indicated by students' responses in their FDG.

Additionally, the survey results showed that affective expression, and open communication were highly reported SP aspects in the two BL courses. This was perhaps due to the reason that the amount of social interaction was great due to courses being taught in face-to-face sessions. Also, online discussions, TBL sessions in class and student group discussions helped to increase the amount of interaction as students were free to express themselves in such groups. Based on the survey results, group cohesion was the least valued aspect among SP elements. This may be because survey questions on group cohesion were mainly measured based on online part of the BL.

Furthermore, questions on a sense of trust and acknowledgement of one's point of view as measured by SP scale, were found to be of less important to students as indicated in their FGD. The fact that online discussions were done mainly at night or during examination times in which students wanted to share examination questions, add to the explanation. Still, the findings of this study showed that students were selective about whom they responded to. Students mainly acknowledged the point of views of their friends or closed groups. In contrast, a study by [19] showed that students perceived stronger teaching and SP in the online section compared to the faceto-face section.

The qualitative results showed that SP was encouraged through the provision of group assignments, teaching presence (teacher online activities), student online and 
offline group discussions, TBL sessions and laboratory works. This finding shows that together with students-based interactive learning activities such as group discussions (where students socialized also), teaching presence is important in influencing social presence. The results of this study add to the importance of student interactions and teaching presence as significant in enhancing SP. Similarly, in [7] SP serves as a platform for communication between instructor and student and students among themselves. Meanwhile, [20] found that teaching presence was necessary to provide guidance and interaction among students in online courses. A study by [21] found SP depended upon participation in the weekly discussions, which encouraged an appreciation for the points of view of others. Additionally, [22] found perceived and actual levels of students' interactivity positively related to students' satisfaction in blended learning. The findings of this study underscore the significance of group discussion in influencing SP. This was evident in the FGD in which almost every respondent mentioned discussion group as their main anchoring point for social interaction and learning.

This study further showed that students felt a powerful sense of belonging (connection) in and with their exclusive face-to -face discussion group members. They were freer to express themselves in such groups than in the whole class sessions. They further felt bonded with members of their exclusive discussion groups and friends. These findings portray that small exclusive group discussions bonded students closer together than large class sessions. These groups tend to augment SP. This might be due to the fact as group size increases, team work and interaction tend to become more complicated as some studies have indicated (cf[23]). Comparably, A study by [23] which investigated the effect of group size on students' perceptions of SP found that students perceived a higher level of SP in smaller groups than in whole class discussions.

Social presence entails interaction and participation. Notably, this study has shown that SP is associated with students' learning. SP influences students' learning through interaction, participation in informal social conversations, TBL sessions, classroom interactions and lab practices. In these settings, students learn various concepts, examination questions, language, grammar, and pronunciation of words.

An interesting finding is that students also use their fellow students" "presence" to enhance their learning by giving names to other students. Such names refer to anatomic or biological structures that students study in their courses. In giving such names, students could link and recall the concepts they study in their BL courses. Other studies on SP and student learning have also related SP to learning. For instance, a study by [16] found SP as a predictor of students' performance in online learning. A study [24] on students' interactions in small private online courses involving medical students in the Netherlands found that students discussed and explained subject content to each other. The study further found that through interaction, most online discussion content was initiated by students themselves and aimed at fellow students, containing about $43 \%$ of social based messages. The findings of this study, like our study, stress on the significance of student interaction in discussion forums as an essential part of learning. The effect of teaching presence in the SP 
Paper-Students' Perceptions of Social Presence in Blended Learning Courses in a Tanzanian Medical...

found in this study, has been supported by [25] whose findings show facilitation as an element of teaching presence in the discussion forum that influences learning.

\section{Conclusion, Implication and Limitations of the Study}

Based on the findings, the following conclusions are drawn: First, Student characteristics such as gender, age and year of study did not have any significant difference regarding the reported scores of SP. This implies that gender, age and year of study are not important variables in influencing SP in these BL courses. This adds to the previous findings that have shown such variables to be of no significance in influencing student perceptions of SP in blended learning courses.

Second, affective expression, and open communication are highly regarded SP elements in the two BL courses. However, group cohesion was the least regarded element of the SP perhaps due its items being mostly focused on online interactions, which were limited in the studied courses as students interacted online mainly at night or during examination times. This implies the need to devise online discussions in such a way that students get maximum interaction and build up cohesion that may help in their learning.

Moreover, both student interactive activities such as group assignments, online and offline group discussions, and teaching presence (teacher online questions, and TBL sessions) are important in encouraging SP. Students felt highly bonded in their exclusive group discussions where they were free to express themselves and share ideas than they were in normal classes. The study also concludes that students felt more connected with their group discussion members and friends than other fellow students in the class. Consequently, there is a need to increase student interactions in the large classes by employing innovative teaching methods such TBL and encourage students to form groups which help in increasing their SP.

Social presence influences students' learning through interaction, participation in informal social discussions, group discussions, TBL sessions, classroom interactions and laboratory practice. This conclusion signifies the importance of small group interactions, and various teaching presence elements in facilitating SP and students' learning.

Nevertheless, this study is limited in the following ways; only one medical university in the country was involved in the study, thus limiting the generalization of the findings to other universities. Future studies need to involve other medical universities involved in offering BL courses. Students involved in the study were those in their first and second years of study taking medical degree only. Therefore, there is a need to involve students in the third, fourth and fifth year from medical and other health related professions to provide a comprehensive picture of the findings. Further studies should also compare the results from medical based universities and other universities providing education in various disciplines such as engineering, social sciences, humanities and education. 


\section{References}

[1] McKerlich, R., Riis, M., Anderson, T., \& Eastman, B. (2011). Student perceptions of teaching presence, social presence and cognitive presence in a virtual world. Journal of Online Learning and Teaching, 7(3), 324.

[2] Picciano, A. G. (2002). Beyond student perceptions: Issues of interaction, presence, and performance in an online course. Journal of Asynchronous learning networks, 6(1): 21-40.

[3] Almasi, M, Zhu, C \& Machumu (2017). Teaching, Social and Cognitive presences and theirrelations to students' characteristics and academic performance in blended learning courses in a Tanzanian University. In Press.

[4] Szeto, E. (2015). Community of Inquiry as an instructional approach: What effects of teaching, social and cognitive presences are there in blended synchronous learning and teaching? Computers \& Education, 81: 191-201. https://doi.org/10.1016/j.compedu.2014. 10.015

[5] Garrison, D. R., Anderson, T., \& Archer, W. (2000). Critical Inquiry in a Text-Based Environment: Computer Conferencing in Higher Education. The Internet and Higher Education, 2: 87-105. https://doi.org/10.1016/S1096-7516(00)00016-6

[6] Garrison, D. R. \& Vaughan, N, D., (2008). Blended learning in higher Education: Frameworks, Principles and Guidelines. John Wiley \& Sons. New York.

[7] Jusoff, K., \& Khodabandelou, R. (2009). Preliminary study on the role of social presence in blended learning environment in higher education. International Education Studies, 2(4): 79. https://doi.org/10.5539/ies.v2n4p79

[8] Garrison, D. R., Cleveland-Innes, M., \& Fung, T. S. (2010). Exploring causal relationships among teaching, cognitive and social presence: Student perceptions of the community of inquiry framework. The internet and higher education, 13(1): 31-36. https://doi.org/10.1016/j.iheduc.2009.10.002

[9] Rourke, L., Anderson, T., Garrison, R. D., \& Walter, A. (2001). Assessing social presence in asynchronous text-based computer based conferencing. Journal of distance education. 14(2):51-70.

[10] Swan, K., Garrison, D. R., \& Richardson, J. C. (2009). A constructivist approach to online learning: The Community of Inquiry framework. In Information technology and constructivism in higher education: Progressive learning frameworks. IGI Global. pp. 43-57 https://doi.org/10.4018/978-1-60566-654-9.ch004

[11] Garrison, D. R. (2007). Online community of inquiry review: Social, cognitive, and teaching presence issues. Journal of Asynchronous Learning Networks, 11(1): 61-72.

[12] Gunawardena, C. N., \& Zittle, F. J. (1997). Social presence as a predictor of satisfaction within a computer-mediated conferencing environment. American journal of distance education, 11(3): 8-26 https://doi.org/10.1080/08923649709526970

[13] Swan, K., \& Shih, L. F. (2005). On the nature and development of social presence in online course discussions. Journal of Asynchronous learning networks, 9(3): 115-136.

[14] Laves, E. (2010). The impact of teaching presence in intensive online courses on perceived learning and sense of community: A mixed methods study (Doctoral dissertation). The University of Nebraska-Lincoln. Retrieved from ProQuest Dissertations and Theses database (Document ID 220163044).

[15] Shea, P., Hayes, S., \& Vickers, J. (2010). Online instructional effort measured through the lens of teaching presence in the community of inquiry framework: A re-examination of measures and approach. The International Review of Research in Open and Distributed Learning, 11(3): 127-154. https://doi.org/10.19173/irrodl.v11i3.915 
Paper-Students' Perceptions of Social Presence in Blended Learning Courses in a Tanzanian Medical...

[16] Richardson, J., \& Swan, K. (2003). Examining social presence in online courses in relation to students 'perceived learning and satisfaction. JALN, 7(1).

[17] Mykota, D., \& Duncan, R. (2007). Learner characteristics as predictors of online social presence. Canadian Journal of Education, 30(1): 157. https://doi.org/10.2307/20466630

[18] Mykota, D. B. (2015). The influence of learner characteristics on social presence. Procedia-Social and Behavioral Sciences, 176:627-632. https://doi.org/10.1016/j.sbs pro.2015.01.520

[19] Bowers, J., \& Kumar, P. (2015). Students' perceptions of teaching and social presence: A comparative analysis of face-to-face and online learning environments. International Journal of Web-Based Learning and Teaching Technologies (IJWLTT), 10(1): 27-44. https://doi.org/10.4018/ijwltt.2015010103

[20] Pawan, F., Paulus, T. M., Yalcin, S., \& Chang, C. F. (2003). Online learning: Patterns of engagement and interaction among in-service teachers. Language Learning and Technology. 7(3):119-40

[21] Picciano, A. G. (2002). Beyond student perceptions: Issues of interaction, presence, and performance in an online course. Journal of Asynchronous learning networks, 6(1): 21-40.

[22] Lin, Y. M., \& Hooft, M. (2008). The impact of blogs on student perceptions toward social interaction and learning satisfaction in blended learning. In International Conference on Computers in Education, Taipei-Taiwan.

[23] Akcaoglu, M., \& Lee, E. (2016). Increasing social presence in online learning through small group discussions. The International Review of Research in Open and Distributed Learning, 17(3). https://doi.org/10.19173/irrodl.v17i3.2293

[24] Uijl, S., Filius, R., \& Ten Cate, O. (2017). Student Interaction in Small Private Online Courses. Medical Science Educator, 27(2): 237-242. https://doi.org/10.1007/s40670-0170380-x

[25] Cheng, C. K., Paré, D. E., Collimore, L. M., \& Joordens, S. (2011). Assessing the effectiveness of a voluntary online discussion forum on improving students' course performance. Computers \& Education, 56(1): 253-261. https://doi.org/10.1016/j.compedu.2010. $\underline{07.024}$

\section{Authors}

Mustapha Almasi is $\mathrm{PhD}$ researcher at the Department of Educational Sciences Vrije, Universiteit Brussel, Brussels, Belgium.

Chang Zhu is Professor at the Department of Educational Sciences, Vrije Universiteit Brussel, Brussels, Belgium.

Article submitted 12 March 2018. Resubmitted 01 May 2018. Final acceptance 02 August 2018. Final version published as submitted by the authors. 